\title{
Multilayer Printing of Complex Antennas Using Aerosol Jet Technology
}

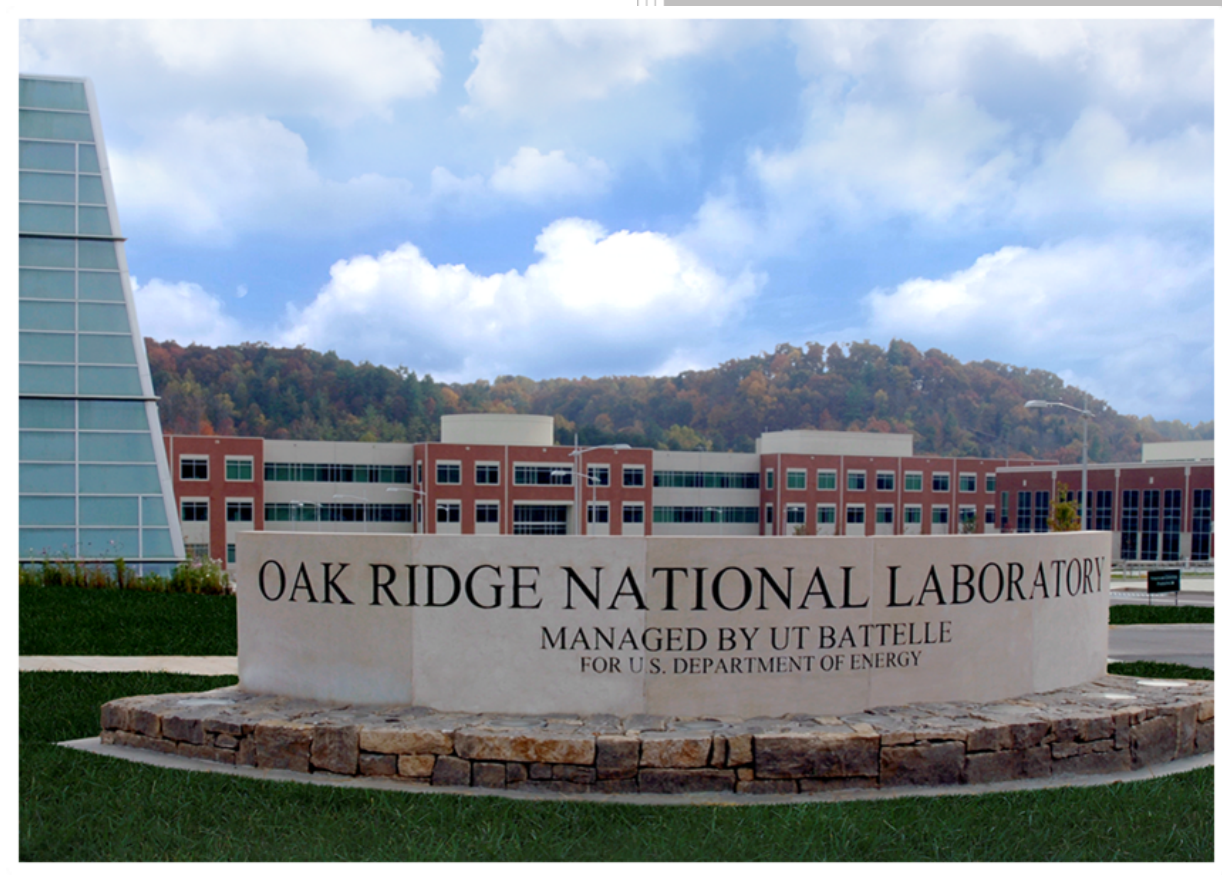

Timothy J. Mclntyre Pooran C. Joshi

CRADA final report for CRADA number NFE-18-07315

Approved for public release. Distribution is unlimited. 


\section{DOCUMENT AVAILABILITY}

Reports produced after January 1, 1996, are generally available free via US Department of Energy (DOE) SciTech Connect.

Website www.osti.gov

Reports produced before January 1, 1996, may be purchased by members of the public from the following source:

National Technical Information Service

5285 Port Royal Road

Springfield, VA 22161

Telephone 703-605-6000 (1-800-553-6847)

TDD 703-487-4639

Fax 703-605-6900

E-mail info@ntis.gov

Website http://classic.ntis.gov/

Reports are available to DOE employees, DOE contractors, Energy Technology Data Exchange representatives, and International Nuclear Information System representatives from the following source:

Office of Scientific and Technical Information

PO Box 62

Oak Ridge, TN 37831

Telephone 865-576-8401

Fax 865-576-5728

E-mail reports@osti.gov

Website http://www.osti.gov/contact.html

This report was prepared as an account of work sponsored by an agency of the United States Government. Neither the United States Government nor any agency thereof, nor any of their employees, makes any warranty, express or implied, or assumes any legal liability or responsibility for the accuracy, completeness, or usefulness of any information, apparatus, product, or process disclosed, or represents that its use would not infringe privately owned rights. Reference herein to any specific commercial product, process, or service by trade name, trademark, manufacturer, or otherwise, does not necessarily constitute or imply its endorsement, recommendation, or favoring by the United States Government or any agency thereof. The views and opinions of authors expressed herein do not necessarily state or reflect those of the United States Government or any agency thereof. 
ORNL/TM-2019/1378

CRADA/NFE-18-07315

Electrical and Electronic Systems Research Division

\title{
MULTILAYER PRINTING OF COMPLEX ANTENNAS USING AEROSOL JET TECHNOLOGY
}

\author{
Timothy J. McIntyre \\ Pooran C. Joshi
}

November 2019

Prepared by

OAK RIDGE NATIONAL LABORATORY

Oak Ridge, Tennessee 37831-6283

managed by

UT-BATTELLE, LLC

for the

US DEPARTMENT OF ENERGY

under contract DE-AC05-00OR22725 


\begin{abstract}
This project demonstrated the feasibility of producing multilayer radio-frequency (RF) and microwavefrequency components using aerosol jet additive manufacturing technology. Funded by the U.S. Department of energy, Advanced Manufacturing Office, this effort focused on novel stacked component designs for devices such as antennas, electronic filters, resistive/inductive/capacitive (RLC) components, and transmission lines. Our approach to RF/microwave component fabrication by aerosol jet printing has the potential to reduce component size, improve performance characteristics, and allow devices to be fabricated on non-planar surfaces. Specifically, folded micro-patch antenna designs were fabricated by stacking layers of conductors and dielectrics printed in sequence using Optomec's aerosol jet technology. ORNL supported the effort by providing design input on printing parameters and characterizing the performance of printed structures. ORNL identified suitable stacked antenna designs, produced finite element models (FEM) in high-frequency simulation software (HFSS), and provided the designs to Optomec for printing. After printing, the devices were tested and characterized at ORNL to determine the frequency response and material characteristics of the printed components. These proof-of-principle devices will provide feedback on printing parameters, optimizations for the FEM models, and a path for more complex multilayer device designs.
\end{abstract}

\title{
1. STATEMENT OF OBJECTIVES
}

The goal of this project was to demonstrate multilayer printing of radio-frequency (RF) antennas. The plan was for Optomec to employ their aerosol jet technology and ORNL to design, simulate, and characterize selected antenna designs for Optomec. The desired outcomes included the following.

- Demonstrate the ability to print multilayer RF/microwave frequency components using aerosol jet technology

- Validate simulation models used to create computer-aided designs (CADs) for printing

- Verify CAD design sensitivity to dimensional changes or imperfections in the printing process

- Demonstrate that device performance matches predictions from HFSS models

- Evaluate the commercial viability of device designs, including packaging for survival in challenging environments

Four tasks were identified to achieve the stated objectives.

1. Printing overview and antenna design selection

2. Simulation of selected antenna designs

3. Print method development

4. Testing and characterization of printed antennas 


\section{BENEFITS TO THE DOE MISSION}

Development of this transformative technology enables the long-sought-after ubiquitous sensor network (USN) architecture envisioned almost 20 years ago and uniquely positions ORNL for additional R\&D opportunities with several DOE programs, including energy-efficient buildings, grid modernization, nuclear facility monitoring, and connected vehicles. In addition, large-scale sensor networks inform climate models that have implications for sustainable energy, water, and agriculture.

\section{TECHNICAL DISCUSSION OF WORK PERFORMED}

Demonstration of printing multilayer RF and microwave circuits using Optomec's aerosol jet printing technology will provide a new avenue for rapid fabrication of complex devices, circuits, and systems. Aerosol jet printing of RF and microwave structures differs from the conventional methods of inkjet, extrusion deposition, and direct-write printing techniques (e.g. silk screen, etc.). Aerosol jet printing does not require the use of complicated curing processes or hazardous chemical agents for etching or metal deposition, which is common in conventional lithographic techniques. Using aerosol jet techniques allows for a more eco-friendly and automated method of producing complex RF and microwave structures and devices. Furthermore, the ability to do rapid prototyping is unparalleled as the printing process can be modified simply by loading a different CAD into the printer.

The ability to print in multiple layers, along with the use of various metallic and dielectric inks, provides a new method of printing stacked RF and microwave components such as capacitors, buried microstrip transmission lines, and dielectric slab waveguides with small feature sizes ( $\sim 10$ microns), in addition to $\mathrm{RF}$ antennas. Moreover, the capability to print multilayer devices can reduce the surface area requirement for components, such as distributed element filters, by transforming the 2D planar component into a stacked 3D component, essentially trading-off surface area for volume to reduce the component footprint. This surface area reduction results in a higher yield and results in manufacturing cost savings.

Reducing the surface area of antennas is critical for ultra-miniature and low-cost sensor development. At the commonly used $915 \mathrm{MHz}$ industrial, scientific, and medical (ISM) frequency band, typical log perioding (YAGI) or dipole antennas have a much larger footprint than the associated electronic circuit and sensing components. A half-wave dipole antenna can be $8-10 \mathrm{~cm}$ or more in size. ORNL has designed a folded micro-patch antenna (Figure 1) $3 \mathrm{~cm}$ long at an operating frequency of $915 \mathrm{MHz}$. The conventional rectangular patch antenna has an electrical length of $\lambda_{\mathrm{o}} / 2$, which is too large at the ISM band of frequencies below $1 \mathrm{GHz}$. In a typical patch antenna, radiation only occurs from the virtual apertures, and the microstrip line can be folded into a more compact configuration. The antenna operation will remain the same provided the aperture is maintained. The antenna design was optimized based on the following parameters: (1) dielectric height as thin as possible, (2) conductors 1 and 3 are connected to the center pin of the coaxial feed cable, (3) conductors 2 and 4 are connected with the side walls and are grounded, (4) ground plane width $D_{t}$ needs to be larger than the strip width $D$, (5) gap $g$ should be equal to dielectric height $h$, and (6) strip width $D$ should be larger than the gap $g$. 


\begin{tabular}{|l|l|}
\hline \multicolumn{2}{|c|}{ Folded Patch Antenna Dimensions } \\
\hline Conductor thickness, $t$ & $0.001 \mathrm{~mm}$ \\
\hline Dielectric height, $h$ & $0.020 \mathrm{~mm}$ \\
\hline Gap, $g(=h)$ & $0.040 \mathrm{~mm}$ \\
\hline Strip Width, $D s$ & $5.0 \mathrm{~mm}$ \\
\hline Ground Plane Width, $D g=(D+8 h)$ & $5.16 \mathrm{~mm}$ \\
\hline Conductor length, $L 1$ & $21.9 \mathrm{~mm}$ \\
\hline Conductor length, $L 2$ & $7.30 \mathrm{~mm}$ \\
\hline$\lambda=2 \times 3(L 1+L 2)$ & $175.2 \mathrm{~mm}$ \\
\hline Dielectric constant, $\varepsilon_{\mathrm{r}}$ & 3.5 \\
\hline Speed of light, $c$ & $3 \times 10^{8} \mathrm{~m} / \mathrm{s}$ \\
\hline
\end{tabular}

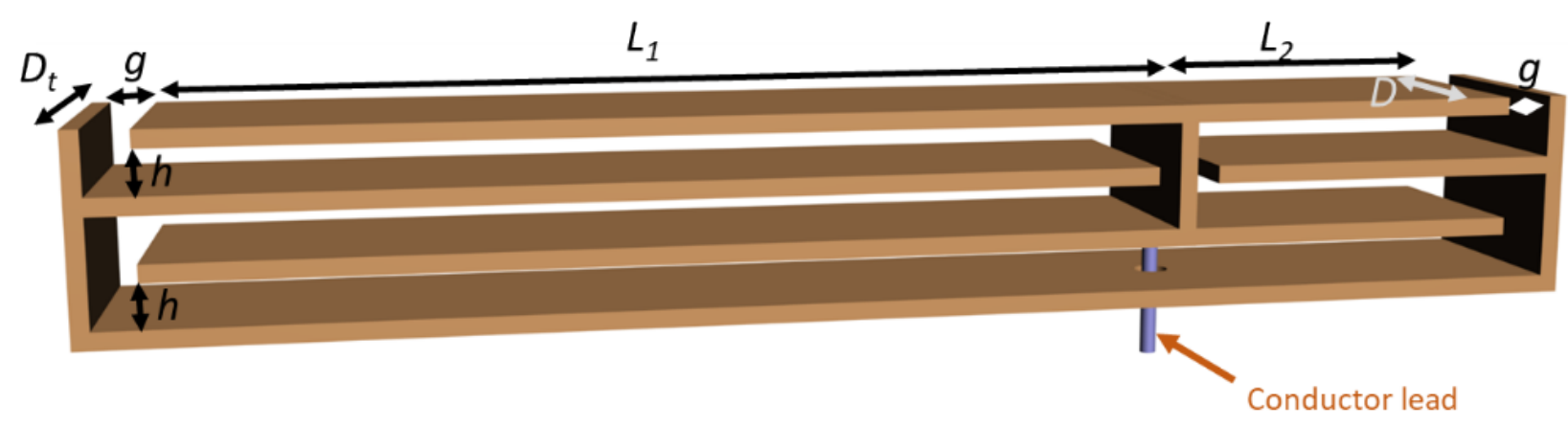

Figure 1. Folded micro-patch antenna with $\mathrm{L1}+\mathrm{L2}$ equal to $\sim 3 \mathrm{~cm}$ in length.

The ANSYS HFSS allows us to simulate 3D full-wave electromagnetic fields to design high-frequency electronics and communication systems. HFSS can generate an appropriate mesh for solving specific application problems. The designer can describe the functional object elements as variables in a table that can be adjusted to observe the effects on performance. Figure 2 shows the simulated frequency response of a micro-path antenna. The antenna shows a $-22 \mathrm{~dB}$ return loss, indicating the antenna and the transmitter impedances are well matched (the smaller the value the better). 


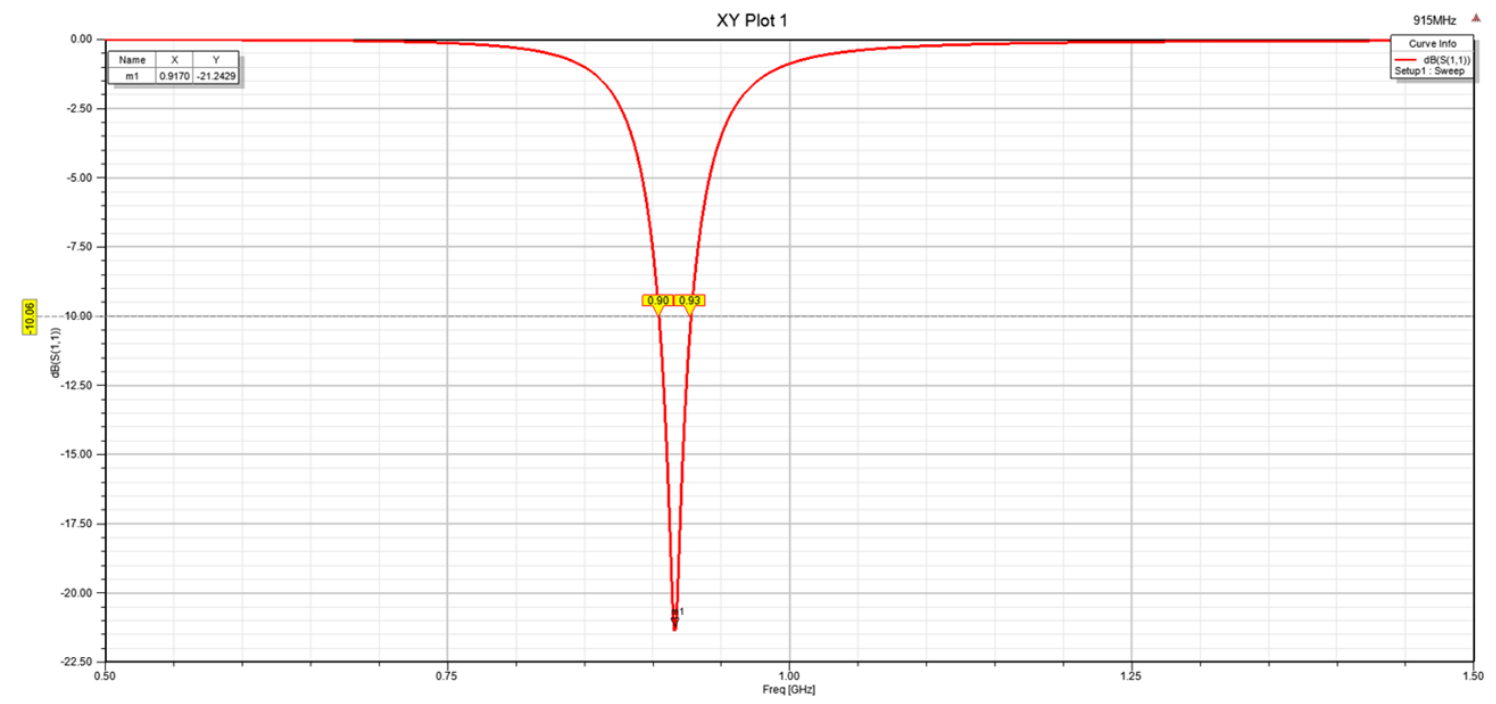

Figure 2. Frequency response curve for the $3 \mathrm{~cm}$ folded micro-patch antenna.

Figure 3 shows the radiation pattern of the antenna in which the z-direction would be pointing out normal to the surface of the antenna. The radiation pattern of the antenna is broad, and the backward radiation is caused by the small dimensions of the ground plane.
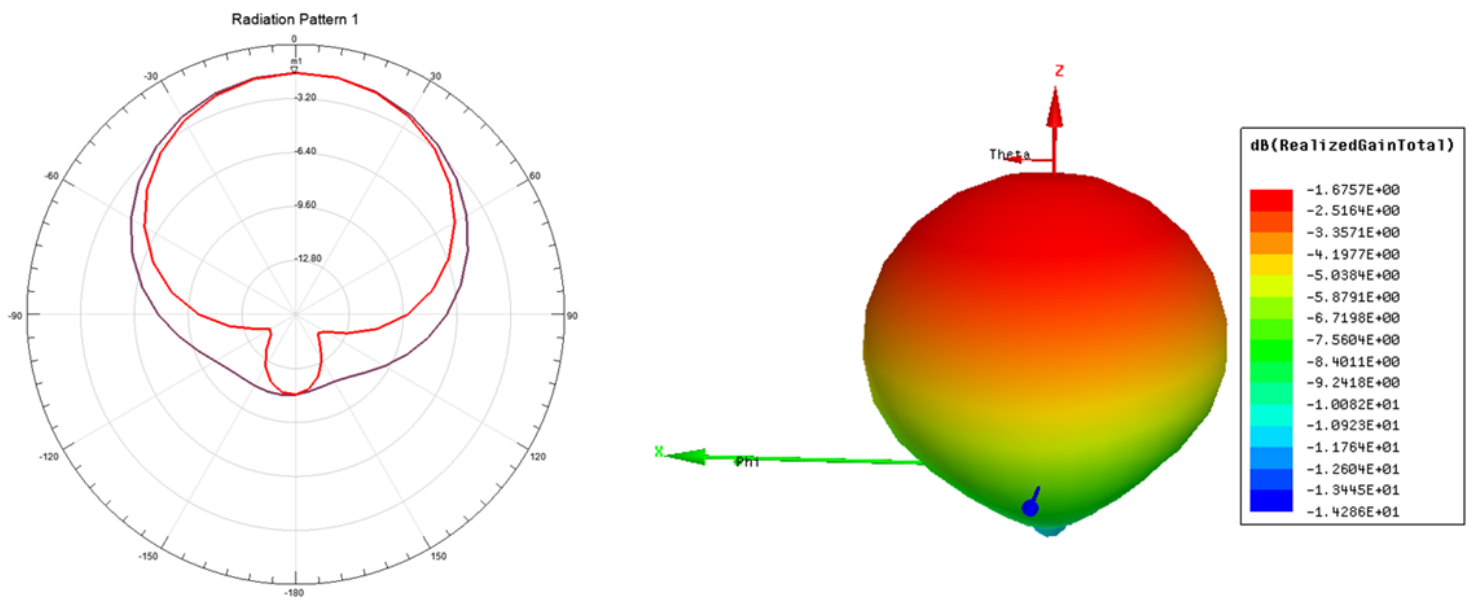

Figure 3. Radiation pattern produced by the folded micro-patch antenna.

These antenna designs were provided to Optomec to assess whether the aerosol jet printer could produce such a complex structure. By examining Figure 1 more closely, one comes to the conclusion that seven layers are required to create this antenna if the aerosol jet printing process is used to stack the layers, one on top of another, in the XY plane. ORNL simulation efforts provide a sense of how the antenna will perform. Figure 4 shows the folded micro-patch antenna that was fabricated by Optomec. The antenna consisted of alternating conductor and dielectric layers to form signal and ground elements. A UV curable dielectric was selected so that the dielectric could be tacked in place as it prints. This tacking helped maintain uniformity and prevented the dielectric from dewetting. Novacentrix N258 was the silver conductive ink, and Norland Electronics Adhesive NEA121 was used as the dielectric. Both inks had long run times and required minimal maintenance during printing, which was critical to implementing the antenna design. Using a combination of pneumatic atomizer (dielectric) and ultrasonic atomizer 
(conductor) modes, a folded patch antenna was successfully printed. Isolation between signal and ground was maintained throughout the seven layers in one case. Between layers, samples were inspected thoroughly and cured. During the printing processed, the dielectric was exposed to UV light for some layers, but a final higher power UV light was needed to fully harden the material. The silver was cured at $200^{\circ} \mathrm{C}$ for a minimum of 2 hours.

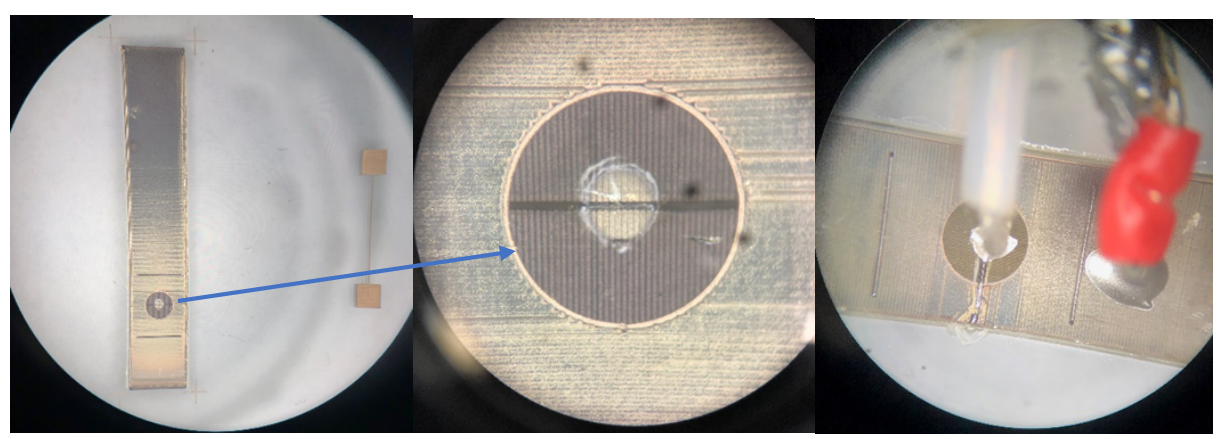

Figure 4. Optomec folded micro-patch antenna, center conductor, and SMA cable connection.

Optomec printed three antennas for RF testing. For RF characterization, the center Subminiature Version A) (SMA) cable was fixed to the Optomec conductor (Figure 4) and the outer shielding was fixed to the surrounding ground. This antenna did not appear to resonate at a particular frequency. However, a response was seen on the network analyzer when a commercial antenna was placed in proximity. Therefore, the antenna is functional and may be operational at $915 \mathrm{MHz}$ with some adjustments and calibration. A screen capture of the network analyzer is shown in Figure 5.

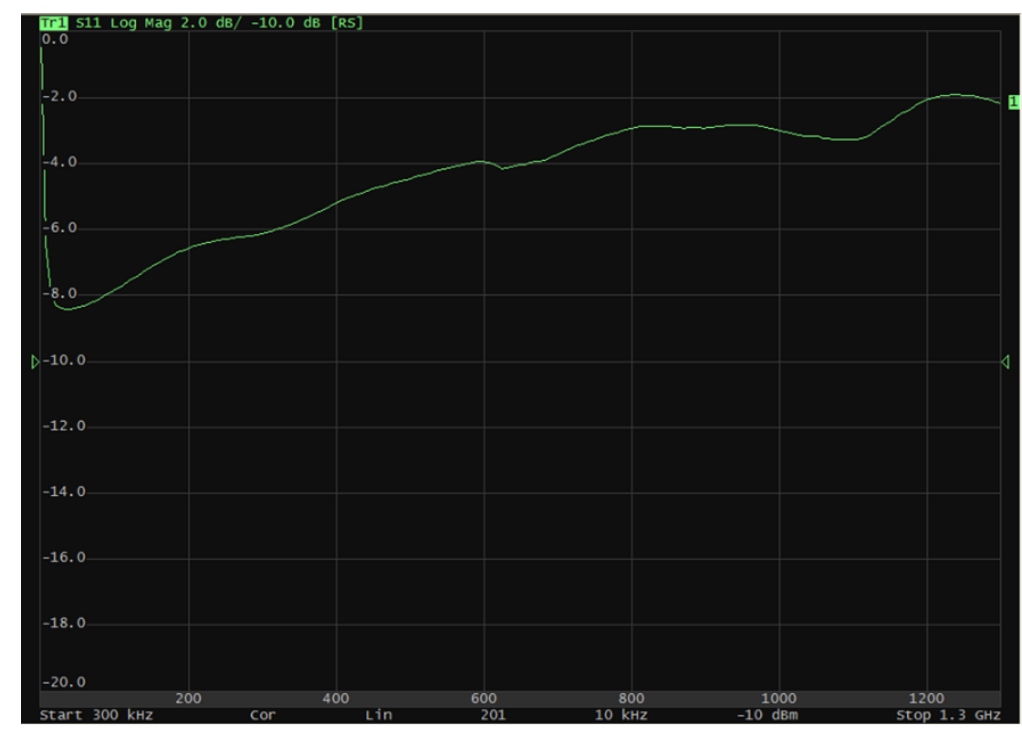

Figure 5. Optomec folded micro-patch antenna network analyzer plot (300 KHz-1.3 GHz sweep).

Overall, with the material selection of Novacentrix N258 and Norland NEA121, a folded patch antenna was successfully printed. Isolation between signal and ground was maintained throughout the seven layers in one case. Layer heights were maintained close to their intended design. As advances in direct-write technology push the limits of print resolution and the available material set for printing expands, small footprint folded patch antennas would directly address the cost, footprint, and integration requirements of flexible hybrid electronics technology. 


\section{SUBJECT INVENTIONS}

No invention disclosures were created during this project.

\section{COMMERCIALIZATION POSSIBILITIES}

Several commercial applications have been identified, including the following.

1. Health monitoring of high-voltage transformers - potential commercialization; Southern Company

2. Monitoring for hydrogen leaks in utility-scale power generation turbines - potential commercialization; Southern Company

3. Health monitoring of large wind turbine blades - potential commercialization; Vestas Corporation

4. Leak detection in municipal gas and water pipelines - potential commercialization; Duraline, Inc.

5. Methane leak detection at capped oil and gas wells - potential commercialization; Pioneer Natural Resources

6. Monitoring for potential fires at e-waste facilities - AON

7. Preventing fires on municipal waste trucks - Waste Management

\subsection{PLANS FOR FUTURE COLLABORATION}

ORNL has already received funding to continue sensor system development from two DOE programs: (1) Office of Electricity, Grid Modernization Laboratory Consortium (OE/GMLC) and (2) Office of Nuclear Energy, Nuclear Energy Emerging Technology (NE/NEET). Partnerships on these projects were formed with the Electric Power Research Institute (EPRI) and Southern Company, respectively. Duraline has developed specific requirements for pipeline leak detection, and follow-up discussions are planned.

We also have plans to explore collaborations with the National Renewable Energy Laboratory (NREL) related to wind turbines and Sandia National Laboratories (SNL) on voltage and current sensors. Finally, the National Energy Technology Laboratory (NETL) is being engaged to accelerate development of gas sensor technologies, focusing on dissolved gas analysis on high-voltage transformers.

\subsection{CONCLUSIONS}

This tech/collaboration project between Optomec and ORNL has achieved success in several areas. Working closely with Optomec to develop multilayer printing capabilities not only expanded the application space for aerosol jet printing technology but also helped Optomec create a whole new class of printed devices for their device library. Building their device library helps them sell machines. The ability to directly print RF structures and devices has also helped ORNL develop collaborations and acquire funding to solve real-world problems using Optomec aerosol jet technology. Finally, ORNL has identified several future collaborative opportunities to develop technology to solve very challenging sensor application issues. Having a powerful team that includes the end user (industry), ORNL technology research and development capabilities, and the printer technology original equipment manufacturer (OEM) Optomec has allowed its members to not only solve immediate challenges facing advanced sensor technology issues but also advance the underpinning fabrication technology to provide new opportunities for sensor development. 
